\title{
eHealth in Europe - Status and Challenges
}

\author{
Anne Moen ${ }^{1}$, Werner O. Hackl ${ }^{2}$, Jacob Hofdijk ${ }^{3}$, Lisette Van Gemert-Pijnen ${ }^{4}$, Elske Ammenwerth ${ }^{2}$, Pirkko Nykänen $^{5}$, \\ Alexander Hoerbst ${ }^{2}$ \\ ${ }^{1}$ Institute for Health and Society, University of Oslo, Norway \\ ${ }^{2}$ UMIT, University for Health Sciences, Medical Informatics and Technology, Austria \\ ${ }^{3}$ CaseMix, the Netherlands \\ ${ }^{4}$ University of Twente, the Netherlands \\ ${ }^{5}$ School of Information Sciences, University of Tampere, Finland
}

\begin{abstract}
Objectives: To present European reflections on the concept of eHealth and report challenges related to further development of eHealth in Europe.

Methods: A survey with 10 questions was distributed to representatives of the national member associations of the European Federation of Medical Informatics (EFMI). The material was summarized using content analysis techniques, generalized and discussed.

Results: The results document a shift from a focus on ICT-orientation to initiatives that will development of the entire health system where eHealth strategies, organizational change, and appropriate technological infrastructure are singled out as important aspects.
\end{abstract}

\section{Correspondence to:}

\section{Anne Moen}

Institute for Health and Society, University of Oslo, Address: P.O.Box 1130, Blindern, N-0318 Oslo, NORWAY

E-mail: anne.moen@medisin.uio.no
Conclusion: There are urgent needs to discuss eHealth strategies and policies to contribute to capacity building necessary to deploy eHealth applications that support sociable services and innovations in health care. As a contribution, the EFMI community will utilize arenas for capacity building on the European level, and stimulate collaboration across national boarders and health systems.

\section{Keywords}

eHealth, status and challenges, Europe, survey

\section{EJBI 2012; 8(1):2-7}

received: December 28, 2011

accepted: March 23, 2012

published: June 15, 2012

\section{Introduction}

Over the last years, health informatics respectively medical informatics has matured. The field is committed to improve quality in health care, provide best evidence at the point of need, and also demonstrate benefits across settings, taking advantage of technological opportunities and applications [1].

On the European scene we observe that the terms health informatics, medical informatics, nursing informatics etc. are gradually substituted or used interchangeably with the term eHealth.

Time is overdue to actively promote health technology based on science-based evidence to ensure that the tools are deployed according to robust evidence [2, 3]. Such evidence would draw from technological, health professional and social perspectives. There are several reports and surveys, 4, 5] providing snapshots and interesting examples for eHealth evolution across Europe.
Publications prepared under the leadership of EFMI also points out key eHealth issues. These issues range from user-involvement and experiences of health professionals and patients working and living in ICT enabled environments [6], health informatics opportunities to deploy, evaluate, and adjust healthcare services [7] to internationally oriented policies and programs to support patient safety [8, interoperability for seamless care [9], cross border care, no boundaries perspectives [10], and adequate business models for health technologies [11.

Achievements in eHealth can support future demands within the health care system and improve the quality of life of citizens, patients and health providers'. The objective of this paper is to discuss the concept of eHealth through a European lens, and present challenges with regard to eHealth in Europe based on a survey administered to the national member societies of European Federation of Medical Informatics (EFMI). We will contribute experience and evidence to discuss current perspectives for eHealth opportunities and challenges identified in Europe. 


\section{Methods and Material}

The current study is based on a survey research methodology. Participants were asked to answer a survey with 10 questions focusing on definitions, trends, challenges and priorities, cultural aspects and ICT infrastructure for the health care system, on an operational as well as strategic level. The questions were:

1. What definition for eHealth is used in your country?

2. What are the key trends and developments in the eHealth domain in your country?

3. What are the main difficulties for the development of eHealth in your country?

4. What are the priorities for the development of eHealth in your country?

5. What are the cultural factors influencing the development of eHealth in your country?

6. What is the link between ICT infrastructure and eHealth development in your country?

7. What is the link between eHealth systems and national health system in your country?

8. Provide evidence on eHealth by citations/copies of surveys, scientific/technical studies, progress/special reports, eHealth education for the workforce.

9. Highlight of one or two shining examples from your country, such as adoption of a national eHealth policy, establishment of a health informatics education program, public-private partnership.

10. What are the lessons to be learned from the country's eHealth experience.

The survey method was selected as it allows for overview and to understand a problem and its reasons by quantifying certain aspects of it. Although trying to quantify certain phenomena the study is primarily exploratory and can give direction for further, detailed research.

\subsection{Data Collection}

Representatives of the 32 national member associations of European Federation of Medical Informatics (EFMI) were identified via www.efmi.org, and invited to answer the questions listed above. They received the questionnaire electronically in July 2011. The national representatives answered the 10 questions on eHealth developments and experiences answered the their country and by their answers contribute with an appraisal of current eHealth developments and experiences in Europe. By October 2011 thirteen responses were received from EFMI members Austria, Croatia, Cyprus, Finland, France, Germany, Iceland, the Netherlands, Norway, Romania, Sweden and Turkey.

\subsection{Data Analysis}

The received answers were subject to qualitative and quantitative content analysis [12]. We sought to identify, abstract and quantify inductively findings from the narrative descriptions of eHealth provided in the national EFMI representatives' answers to the questions. We started off to summarize the descriptions and definitions of eHealth, and continued to extract and generalize eHealth challenges. The categories are labelled requirements, prerequisites, difficulties and obstacles encountered in the development and implementation of eHealth in Europe. As a first step, statements were extracted from all answers received, and then annotated and generalized by two researchers (WOH, AH). Based on the generalized statements disjunctive categories were grouped inductively by a team of four (WOH, AH, JH, AM). Arriving at a consistent set of categories required three revision cycles.

In addition, we quantified the material by counting the number of statements assigned to each generalized category. A relative weighting factor, for each category was then calculated by dividing the counts of statements for a category by the overall sum of statements (see table 1 for details). This factor was used in the final step when we created the tag cloud (see figure 1) to illustrate the relative importance of each category, expressed as font size for each tag.

\section{Results}

The responses to the survey were narrative descriptions related to each of the 10 questions. In this report of results we will therefore elaborate findings about the concept of eHealth (section 3.1), services and challenges related to eHealth initiatives (section 3.2), and challenges for eHealth deployment (section 3.3).

\subsection{Descriptions of the Concept of eHealth}

To better understand and appreciate the developments and initiatives across European countries in terms of eHealth it is necessary to establish a shared understanding of what is understood by the concept of eHealth.

In the narrative descriptions, the understanding of eHealth converges as a common name for design, development, implementation and evaluation of ICT in the health system, broadly understood. Drawing from the responses we see a consensus and convergence that eHealth primarily relates to the use and introduction of information and communication technology (ICT) in a practice, but also to calls for cross-institutional and interdisciplinary understanding of eHealth. Collaborative efforts and new way(s) of working in healthcare require arenas for interactions to attend to the needs by stakeholders including health professionals, patients or their relatives. Three descriptions stated explicitly that eHealth is not 
just the use of ICT in health care, but should be considered broadly in relation to the plethora of needs within the healthcare system. ICT is an important, but not sufficient enabler to meet challenges in and to the national health care systems across Europe.

In line with previously published descriptions of eHealth [13, 14, the broader aim of eHealth is to support health professionals in their work and continuous, lifelong learning, as well as to assist all citizens in their own health care management and their search for reliable health information, disregarding organizational boundaries and functioning of the health systems. The provided descriptions allude to previously reported potentials of eHealth as contributor to meet challenges for health care provision and improve the health system across Europe [4, 13. Privacy, security and the use of standards were seen as given; important, general requirements for achievements in eHealth. We found agreement in the narrative descriptions suggesting that for future developments in eHealth active integration to allow opportunities for participation by all citizens is required. eHealth should therefore not be restricted to health professionals.

\section{2 eHealth Applications and Services}

The majority of the responses contained examples of important initiatives to provide high quality health information for use at the point of need. Grouping the content in the narrative descriptions provided examples ranging from technical and social infrastructure for secure access to health data and strategies for collaboration of providers and patients; repositories and suits of applications for digital clinical records; and tools to actively encourage participation by patients.

A striking finding in the responses is that similar types of services are named differently. Likewise, the reports showed that infrastructure and connectivity to share information across different levels of care, between care facilities or providers or patients and relatives are considerable challenges across Europe. Along the same lines, several connected deployment and use of services that enable citizen to access their health data securely and participate in their treatment, care and health prevention to the current state of (poor) Internet access for citizens.

Overall, in their answers, representatives of the EFMI national member societies report on the importance of national leadership and a national eHealth strategy including administrative, professional and citizens' perspectives. In some countries regional strategies accompany the national strategy. The progress in deployment of services and applications varies. To elaborate on the deployment we clustered the reported initiatives as "technical and social eHealth infrastructure", "eHealth repositories" and "eHealth applications" based on the collected material.

Technical and social eHealth infrastructure would provide opportunities for secure, seamless transmission of health information between home care/primary care, hospitals and GPs, and between public and private health sector. Examples include efforts for data exchange and interoperability in terms of terminology, ontology and standard development, protocols for information sharing and semantic interoperability, as well as legal and ethical issues for correct authentication, confidentiality and maintained trust. eCards, eSignature, unique identifiers for patients and providers, and protocols for electronic exchange of health Information are examples pointing to the technical and social eHealth infrastructure.

eHealth repositories would be Electronic Health Records and Patient portals, and there is a plethora of labels reported including DMP, EPR, EHR, longitudinal medical record, eArchive or eView. Patients and healthcare professionals should be able to securely access resources in an eHealth repository for purposes of coordination, continuity, and self-management. A study from Germany and Austria indicates high interest of patients respectively citizens on these technologies [15. The DMP (dossier médical personnel) initiative in France illustrates interdependent efforts for inter-operability, security of systems, organization of services and involvement of all stakeholders to develop a coherent e-health "ecosystem" [16]. The variety of different requirements to eHealth repositories respectively Electronic Health Records across Europe is covered in a systematic review by Hoerbst and Ammenwerth [17.

eHealth applications are specific services for workflow support and interaction between providers and patients across time and space given available eHealth infrastructures and repositories. Services like eReferral, Patient Summary and eDischarge, ePrescription and eMedication, eRadiology, eLaboratory, eCare Coordination and eSurveillance as well as Telemedicine and eServices for citizens are identified as building blocks.

Patient summaries and eDischarge applications offer a structured, focused summary of clinical findings from a health encounter. A study from Austria for example reports high satisfaction and positive impact of electronic communication of discharge letter between hospitals and GPs [18. A survey from Scotland reports that eDischarge letter is faster and may lead to noteworthy cost savings 19]. ePrescription and eMedication refers to electronic support to the chain of actions in medication prescription. A study from Sweden reports that physicians were generally satisfied with their specific EHR-system and with the available ePrescribing functionality [20]. eReferral and eBooking automates the scheduling process to health care service. A survey from Scotland showed modest rates of adoption for e-referrals [21. In a study of eRadiology, sharing MRI images between smaller and larger hospitals are reported as promising [22. In the field of eMonitoring and telemedicine several studies from European colleagues report benefits for chronically ill patients. For example, telemonitoring of the lung function of patients affected by Cystic Fibrosis led to less hospitalization and reported economical saving [23], and home spirometry for outpatient lung transplants showed that eMonitoring was feasible, safe, and decreased anxiety [24]. Telemedicine 


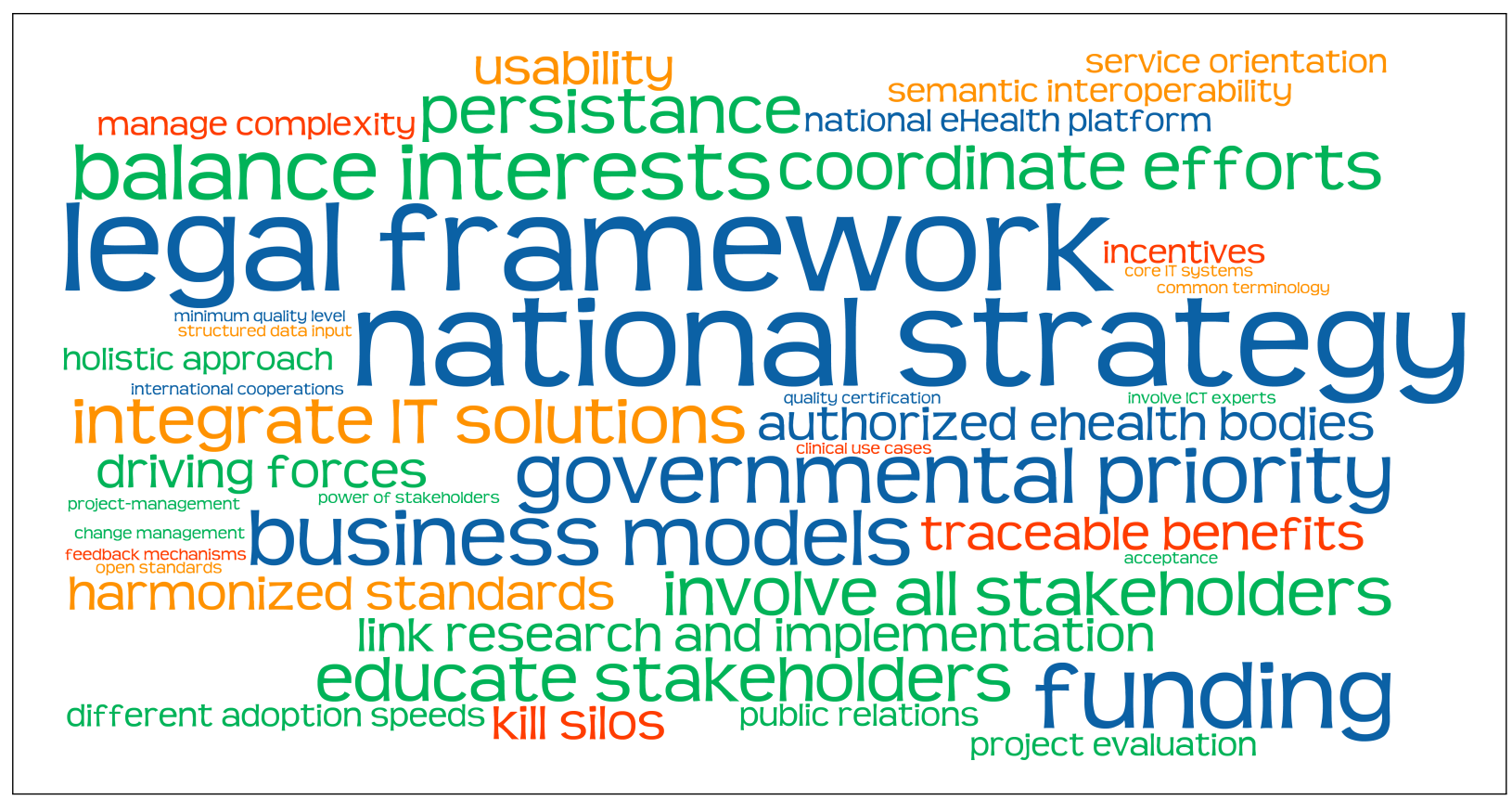

Figure 1: eHealth challenges, relative frequency correlates with font size.

enabled eConsultation facilitates supervised care, reduction of outpatient visits and more timely appointments [25, 26. A study of telemedicine supported thrombolytic treatment of acute ischemic stroke in Denmark suggests that the macroeconomic costs may balance with savings in care and rehabilitation services within 2 years, and although long-term calculations are uncertain, potentially large long-term savings are associated with telemedicine support to this treatment [27. In the area of eCoordination, evaluation of support for home care document improved communication, coordination and collaboration among nurses, psychologists and doctors 28. And lastly, in a study of eService for patients, the authors report that a personal health record (PHR) did not increase patient empowerment, but, at the same time, a PHR did not have any significant adverse effects either 29 .

\subsection{Challenges for eHealth Deployment}

Further categorizing the challenges found in the narrative descriptions about eHealth deployment in Europe gives the following picture (figure 1).

Figure 1 illustrates that quite heterogeneous challenges to eHealth deployment are reported in the received descriptions. We acknowledge that there are several ways to interpret the information in this tag cloud. For this presentation we choose to zoom in on the following dimensions: 'strategy policy', - 'technological' and 'organizational' - 'professional' to elaborate the perspectives for an integral or holistic perspective on eHealth.

Counts of frequencies, understood as how often we interpreted content of the narrative descriptions, are grouped in these dimensions and presented in Table 1.
The reader of the table and the tag cloud would be struck by the prominence of the strategy \& policy - technical dimension. In the tag cloud strategy \& policy is presented as blue colour, and technical is presented as orange colour. The importance of an appropriate legal framework and national strategy with sufficient funding is noticeably expressed by this dimension, and point towards a call for governmental priority to authorize eHealth bodies.

Another aspect is the strong national focus, and in the material from our respondents we only found the importance of international cooperation mentioned once. The technical dimension relates to efforts to establish a sound eHealth platform. The answers tap into well known challenges in the health informatics community, including efforts to harmonize standards, support semantic interoperability, optimize usability for integration of new and existing IT-solutions demonstrating a service orientation, and support the mobility of patients and health professionals.

In terms of the organizational dimensions, presented as green in the tag cloud, and the professional dimensions, presented as red-orange in the tag cloud, other issues stood out. As for organizational dimensions, the importance to balance interest between private and public sector, involving and educating all stakeholders, handle persistence and initiate change management and importance of driving forces for coordinated efforts stood out.

Clustered as the professional dimension are issues that relate to inherent complexity of clinical practice and the variety of professional issues that surface following development and introduction of eHealth across Europe. The importance of traceable benefits visible to all parties and appropriate incentives can help overcome challenges of "silo thinking" and lack of cooperation. 
Table 1: Basic categories for eHealth challenges, grouped with frequency in the narrative descriptions.

\begin{tabular}{|c|c|c|c|}
\hline \multicolumn{4}{|c|}{ Strategy \& policy - Technological } \\
\hline legal framework & 8 & integrate IT solutions & 4 \\
\hline national strategy & 8 & harmonized standards & 3 \\
\hline funding & 6 & usability & 3 \\
\hline business models & 5 & semantic interoperability & 2 \\
\hline governmental priority & 5 & service orientation & 2 \\
\hline authorized eHealth bodies & 3 & common terminology & 1 \\
\hline national eHealth platform & 2 & core IT systems & 1 \\
\hline international cooperation & 1 & open standards & 1 \\
\hline minimum quality level & 1 & structured data input & 1 \\
\hline quality certification & 1 & & \\
\hline \multicolumn{4}{|c|}{ Organizational - Professional } \\
\hline balance interests & 5 & kill silos & 3 \\
\hline coordinate efforts & 4 & traceable benefits & 3 \\
\hline educate stakeholders & 4 & incentives & 2 \\
\hline involve all stakeholders & 4 & manage complexity & 2 \\
\hline persistence & 4 & acceptance & 1 \\
\hline driving forces & 3 & clinical use cases & 1 \\
\hline link research and implementation & 3 & feedback mechanisms & 1 \\
\hline different adoption speeds & 2 & & \\
\hline holistic approach & 2 & & \\
\hline project evaluation & 2 & & \\
\hline public relations & 2 & & \\
\hline change management & 1 & & \\
\hline involve ICT experts & 1 & & \\
\hline power of stakeholders & 1 & & \\
\hline project-management & 1 & & \\
\hline
\end{tabular}

\section{Discussion \& Conclusion}

The findings from analysis of the narrative descriptions point to important challenges related to eHealth in Europe. This is indeed an evolving field where there is a lot of activity, and our respondents added interesting national perspectives that add to previous reports [5]. The four dimensions identified in the responses to our 10-question survey are important starting points for further research and development to constitute progress in the eHealth area. The most important insight from this study is an urgent need to ensure that eHealth strategies and policies for further design and deployment of eHealth applications support sociable services and innovations in health care. Reported diversity in the current eHealth development and exploitation in Europe support a shift from a strict focus on ICT implementation to a comprehensive, holistic approach acknowledging that eHealth involves interplay of appropriate technical and social infrastructure, secure repositories and usable applications [3, 8]. The next steps would be to ensure that existing and new applications support sociable services and innovations in health care. More information about the interplay of product, project and impact evaluation to link research and implementation should be collected as evidence to enable learning from accumulating experiences.

Although this survey focused largely on national issues, the report highlights important challenges to overcome for future development of eHealth. We consider the emphasis on the policy \& strategic, technological, organizational, and professional dimensions related to eHealth as overlapping and highly interdependent. The implica- tions would be that the upcoming challenges should be approached and addressed by taking these dimensions into account 6]. Although the accumulated evidence demonstrates the complexity and importance of multiple interacting perspectives, more research on the interactions and implications of scientific findings for the everyday practice are needed for further achievements in eHealth.

Among important initiatives would be to create arenas for capacity building, exchange of experiences and new initiatives to bridge across the national concern. Concretely the EFMI community will contribute to capacity building and exchange in focused efforts in international meetings, and stimulate their national member associations to exchange their experiences for collaboration across national boarders and health systems.

There are obvious limitations to this survey, specifically reflected in the composition of the sample, and what those who responded chose to highlight from their country to answer the questions. The smaller cohort of the national member associations that chose to answer to the questions, thus limiting the representativeness of the results presented here. However, the findings are related to reported, on-going efforts across Europe, and this should add some to alleviate these limitations.

In conclusion, let us point out similarities in the identified challenges, specifically related to strategy \& policy for eHealth across the received narrative descriptions. We believe lack of reference to ongoing efforts in other countries as well as meager attention to European leadership can point in the direction of national eHealth silos. Priorities in eHealth may be perceived as a national issue, since health care is a national responsibility across Eu- 
rope. However, priorities stated on the European level 30 coupled with concerted efforts more broadly in the EFMI community can be a leading force for progress across the region, and influence the emphasis in eHealth policy and strategy nationally.

\section{Acknowledgements}

We acknowledge contributions from our colleagues in the EFMI community (alphabetic order); Britta Böckmann, Anita Burgun-Parenthoine, Nihal Dizdar, Valgerður Gunnarsdóttir, Mira Hercigonja-Szekeres, Antonis Jossif, Gunnar Klein, Sabine Koch, Oleg Yu Mayorov, George Mihalas, Ragnar Nordberg, Günter Schreier, and Brigitte Seroussi.

\section{References}

[1] Haux R. Medical informatics: Past, present, future. Int J Med Inf. $2010 ; 79(599)$

[2] Rigby M, Brender J, Beuscart-Zephir M, Hyppönen H, Nykänen P, Talmon J, et al. Next Steps in Evaluation and Evidence - from Generic to Context-Related, pp. 208-212. In: Moen A, et.al, editor. User-centred Networked Care. IOS Press; 2011.

[3] van Gemert-Pijnen J, Nijland N, Van Limburg M, Ossebaard H, Kelders S, Eysenbach G, et al. A holistic framework to improve the uptake and impact of eHealth technologies. J Med Internet Res. 2010; 13(4):e111.

[4] Stroetmann KA, Altmann J, Stroetmann VN, Protti D, Dumortier J, Giest S, et al. European countries on their journey to national eHealth infrastructures. Final Strategic Progress Report. Berlin, Germany: Empirica 2011.

[5] Andreassen HK, Sorensen T, Kummervold PE. eHealth trends actoss Europe 2005-2007. Tromso: National Center for Collaborative care and Telemedicine; 2007.

[6] Moen A, Andersen SK, Aarts J, Hurlen P, editors. User Centred Networked Health Care. IOS Press; 2011.

[7] Andersen SK, Klein, G, Schulz S, Aarts J, Mazzoleni MC, editors. eHealth Beyond the Horizon - Get IT There. IOS press; 2008

[8] Nohr C, Aarts J, editors. Information Technology in Health Care: Socio-Technical Approaches 2010. From Safe Systems to Patient Safety. IOS Press; 2010.

[9] Blobel B, Hvannberg E, Gunnarsdóttir V, editors. Seamless Care - Safe Care, The Challenges of Interoperability and Patient Safety in Health Care. IOS Press; 2010.

[10] Stoicu-Tivadar L, Blobel B, Marcun T, Orel A, editors. eHealth Across Borders Without Boundaries. E-salus trans confinia sine finibus. IOS Press; 2011.

[11] van Limburg M, van Gemert-Pijnen JE, Nijland N, Ossebaard HC, Hendrix RMG, Seydel ER. Why Business Modelling is crucial in the development of eHealth technologies. J Med Internet Res. 2011;11(3):e41.

[12] Mayring P. Qualitative Content Analysis. Forum Qualitative Sozialforschung/Forum Qualitative Social Research (serial on the Internet) 2000;1(2).

[13] Eysenbach G. What is e-health? J Med Internet Res $2001 ; 3(2): \mathrm{e} 20$
[14] Eysenbach G. Medicine 2.0: social networking, collaboration, participation, apomediation, and openness. J Med Internet Res $2008 ; 10(3)$

[15] Hoerbst A, Kohl C, Knaup P, Ammenwerth E. Attitudes and behaviors related to the introduction of electronic health records among Austrian and German citizens. Int J Med Inform. 2010;79(2):81-9.

[16] ASIP Sánte. The DMP: a project that is structuring the development of e-health in France. 2010: [cited 2011 Nov 3] Available from: http://esante.gouv.fr/en/dossiers/dmp-a-projectstructuring-development-e-health-france.

[17] Hoerbst A, Ammenwerth E. Electronic health records. A systematic review on quality requirements. Methods Inf Med 2010;49(4):320-36

[18] Machan C, Ammenwerth E, Schabetsberger T. Evaluation of the electronic transmission of medical findings from hospitals to practitioners by triangulation. Methods Inf Med 2006;45(2):225-33

[19] Pillai A, Thomas SS, Garg M. The electronic immediate discharge document: experience from the South West of Scotland. Inform Prim Care. 2004;12(2):67-73.

[20] Hellström L, Waern K, Montelius E, Astrand B, Rydberg T, Petersson G. Physicians' attitudes towards ePrescribingevaluation of a Swedish full-scale implementation. BMC Med Inform Decis Mak 2009; $\operatorname{Aug}(7): 9-37$

[21] Pagliari C, Donnan P, Morrison J, Ricketts I, Gregor P, Sullivan F. Adoption and perception of electronic clinical communications in Scotland. Inform Prim Care 2005;13(2):97-104.

[22] Marthinsen PB, Hald J, Bergstrom R, Jakobsen J, Christensen $\mathrm{D}$, Roterud $\mathrm{H}$, et al. The multimedia, virtual MR imaging department, clinical aspects. Int J CARS. 2009;3(S1):155-63.

[23] Murgia F, Cilli M, Renzetti E, Popa N, Romano T, Alghisi $\mathrm{F}$, et al. Economic evaluation of telehomecare in chronic lung diseases. Clin Ter 2011;162(2):e43-9.

[24] Sengpiel J, Fuehner T, Kugler C, Avsar M, Bodmann I, Boemke A, et al. Use of telehealth technology for home spirometry after lung transplantation: a randomized controlled trial. Prog Transplant 2010;20(4):310-7.

[25] Harno K, Ruotsalainen P. Sharable EHR systems in Finland, pp. 364-70. In Bos, L et.al. editors. Medical and Care Compunetics 3, IOS Press; 2006

[26] Nijland N, van Gemert-Pijnen JE, Boer H, Steehouder MF, ER. S. Increasing the use of e-consultation in primary care: results of an online survey among non-users of e-consultation. Int J Med Inform 2009;78(10):688-703.

[27] Ehlers L, Müskens WM, Jensen LG, Kjolby M, G. A. National use of thrombolysis with alteplase for acute ischaemic stroke via telemedicine in Denmark: a model of budgetary impact and cost effectiveness. CNS Drugs 2008;22(1):73-81.

[28] Pitsillides A, Samaras G, Pitsillides B, Georgiades D, Andreous P, Christodoulou E. DITIS: Virtual Collaborative Teams for Home Healthcare. J Mob Multimedia 2006;2(1).

[29] Tuil W, Verhaak C, Braat D, de Vries Robbe P, Kremer J. Empowering patients undergoing in vitro fertilization by providing Internet access to medical data. Fertil Steril 2007;88(2):361-8.

[30] Commission of the European Communities. Communication from the Commission to the Council, the European Parliament, the European Economic and Social Committee and the Committee of the Regions: e-Health-making health care better for European citizens: An action plan for a European eHealth Area. Brussels; 2004. 